\title{
Morteza Farhadi, Vernacularism Perspective among Iranian anthropologists
}

Reviewed by

\section{Nazanin Gharaeinejad}

Faculty of Foreign Languages and Literature, English Department,University of Tehran, Iran. Mail Id: n__gh64@yahoo.com | ORCID ID: 0000-0001-5309-3528

\section{Ali Khanmohmmadi \\ Master student of Cultural Studies at AllamehTabataba'i University in Iran. \\ Mail Id: ali1992khanmohammadi@gmail.com | ORCID ID: 0000-0003-0768-4217}

\section{Bibliographic Information:}

Name of the Book: The culture of co-operation in Iran, An Introduction to Anthropology and Sociology of co-operation.Book1: Traditional co-operation in Irrigation and Agriculture.

Author: Morteza Farhadi

Publisher:Nashr-e Daneshgahi

Language: English

ISBN-978964017027

Price: 130500 Rial / 0.476 Dollar

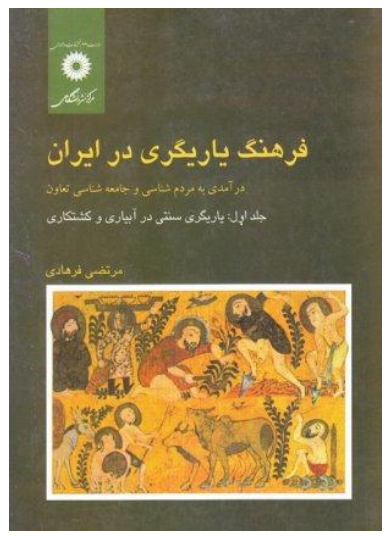

Anthropology of Development isa branch of anthropology that studies development as a scientific object from a critical perspective.These anthropologists mainlyattempt to adjustment the economic, technical, political, or social life of a particular place, especially in slums and colonies.Unlike Development anthropology, this branch of anthropology does not neglect the impact of colonialism on backwardness. This branch moves in one direction of postcolonial studies with the critique of colonialism.

Development can be considered both a simplification of economic indicators and an elusive concept that induces a vague myth. But mostly "modernization" has understood development in the first discourse."Traditions", "Rural life" and "Folklore" were common groundtoo many Asian civilizations. Especially, with the predominance of "Modernization" in many Asian countries such as Iran, the study of these elements was rejected. Because modernization was anidentical program of change, therefore itdestroyed any other differences with its specified system.In the 1960s, unlike to the current of archeology in Iranian studies and educational and cultural institutions, studies 
were also conducted in anthropology of Iran.On the other hand, "Modernization" in Iran makes thedouble suffering of the lower classes in Iran, including the nomads and the farmers. Emerging the vernacularism Perspective within the context of the "Iranian Anthropology" was the best answer to this problem. In other words, theresearch of these anthropologists- like the anthropology of development research of development- had much consideration to Iran's climatic and cultural issues. This field research has been prepared by using ethnography, monograph, and participation during decades. Rural studies and nomadic studies have provided another account of the relation between the Iranian and nature. This narrative pays attention to the traditions of different cultural groups.

There are different narratives and typologies of pre-modern Iranians in the books of these anthropologists. The texts of non-Iranian writers, often influenced by the Orientalist approach, shown Iranians as passive and egocentric. Although, all of these classifications have been written without concern to the arid / waterlogged climate and cultural diversity of Iran.MortezaFarhadi is a researcher and professor of anthropology who is well-known for his numerous researches in the field of anthropology of development and rural anthropology in Iran.He has published 12 books, 77 articles and scientific notes during his more than 50 years of scientific activity. This text introduces Farhadi's views by reviewing the book "The culture of co-operation in Iran". This book is the winner of the thirteenth world award for book of the year of the I.R.I and one of his most important works.Cooperation issue is a feature of a traditional society. Whereas a significant part of Iranian society did not enter the modern urban milieu by the mid-1950s, Co-operation issue was great importance. Cooperationissue means uniting and aligning the efforts of two or more people to achieve a specific goal or goals with a single or different intention and goal.In social life, both in its primary form and in its advanced form, the culture of co-operation in various fields such as work, production, services, cultural and social activities is one of the most important factors, thus it can be said that social life is not possible without help and cooperation.Iran is a special phenomenon both in terms of history and the experience of many changes and conflicts, both in terms of climate diversity and in terms of ethnicities with different cultures. In the corners of the north, south, west, east and center, masses of types of spontaneous public assistance have emerged, which have been organized under the influence of environmental factors and local needs and have sustained from generation to generation. Therefore, the "The culture of co-operation in Iran".is the first work that has provided a serious and comprehensive analysis of the structure and position of traditional cooperatives in Iranian society. The current book is the first volume of a three-volume collection, the second and third volumes of which have not yet been published. This volume introduces traditional helping organizations in the field of irrigation and agriculture, and the second and third volumes, which have not yet been published, include other traditional assistance in the fields of livestock, food, and clothing, hunting and fishing, as well as domestic products, roads, and family and public buildings, celebrations and mourning, education and its consequences. Obviously, two other valuable books have been published by author. The first is the Anthropology of Co-operation, which deals with the theoretical aspects of help and was published in 2009. The second is Clause (An Introduction to the Anthropology and Sociology of Cooperation), which examines and theorizes traditional women's cooperatives in Iran, published in 2002.Farhadi helps to encounter therequire for research and study 
of Iranian vernacularism culture. The axis of formation of the assistances mentioned in this book is mostly "economic", but other factors have affected the stability and permanence of such assistances. Just a few pages of this book are enough to tempt the reader to read the book.Before addressing the co-operation issue, Farhadi emphasizes the need to research and study the vernacularism culture of Iran; because he believes that the lack of comprehensive study and knowledge of vernacularism culture has led to irreparable economic, social and psychological trauma. Hence, he addresses three important subjects in Iranian agriculture that have been neglected:Firstly, Drying of aqueducts or aqueducts in desert and semi-desert areas is due to digging deep wells; secondly, Iranian agriculture and fertilizer. In traditional Iranian agriculture, one of the ways to prepare fertilizer was to use dome-shaped towers; Thirdly, Iranian agriculture is a traditional cooperative.The main idea in creating a cooperative is based on the principle that people come together to cooperate. Hence, cooperatives achieved this principle. The foundation of traditional cooperatives is focused on selfreliance.But government policies moved to be replaced by formal cooperatives which modeled on Western cooperatives. Hence, cooperatives are based on "trade and commerce." Therefore, it was in conflict with the principle of cooperatives and traditional cooperatives, and eventually led to the elimination of traditional cooperatives.

The first volume has a preface and three sections, and each section is divided into several chapters. The preface is obviously devoted to describing the subject of the work and expressing the author's motivation and method of collecting information and introducing the book chapters. First section, Generalities, which consists of three chapters. These chapters consist of an introduction that includes the urgency for vernacularism study and awareness of helping culture and assisting, literature review and typology of Participatory development in Iran. The third chapter of the first section is the most important chapter of the book in which the author discusses the general classification and naming of types of assistance, and the classification of social groups based on the type of cooperation. Second section, contributing to water and participatory irrigation, which has two chapters. This section is definitely dedicated to introducing and analyzing various types of help related to water and irrigation. The second chapter of the second section introduces the traditional help in holding celebrations and performing ceremonies and rituals related to water and irrigation.

Third section, Cooperative and participatory development in the field of agriculture, which has three chapters. Finally, the third section is devoted to the introduction and analysis of helping development in the field of agriculture. The first chapter of the third section introduces the types of cooperation in the field of agriculture and the types of assistance in planting and harvesting agricultural products, andalso in the second chapter, states the climatic and geographical coordinates. Obviously, in the third chapter, the types of help in the field of gardening are discussed. Book appendices include illustrations and drafts, also oral sources (narrators and interviewees) and written sources (books, articles, pamphlets, dissertations, manuscripts, and notes), as well as a list of names, locations. , cultures, foods, animals and local idioms and vocabulary, complete the book.

Considering the similarities of postcolonial perspectivein relation to "Otherness postcolonial theory" with Farhadi'sview, on the other hand, there are differences between his vision and these 
theories.The current book considers the solution of sustainable development from within Iranian traditions. Therefore, He does not consider development as a product of the West. He also does not consider the West as a standard for this development.He has also emphasized both sustainable development and participatory development in his works. Farhadi especially createdthe cooperative development.He considers development as an endogenous and historical process. This process is made by the efforts of Iranian peasants, tribes, and women, not by Western books and universities. With detailed ethnographies, Farhadi tries to produce concepts and principles outside of Western knowledge. Therefore, he lived in the villages of the central and western regions of Iran for more than a decade. Consequently, in the present book, "The culture of co-operation in Iran", Farhadi describes the ways of the past to achieve participatory development.

\section{Reviewer's details:}

\section{Reviewer One: Nazanin Gharaeinejad}

PhD studentin English Language and Literature,Faculty of Foreign Languages and Literature, English Department, University of Tehran

Instructor,Shariati Technical and Vocational College,Tehran, Iran.Interdisciplinary Researcher and literary critic in critical theories, Cultural Studies.Latest presentation: "Modernity: the subjectivity of modern human", The Deputy Minister of Culture and Social Affairs, AllamehTabataba'i University, Tehran, Iran.

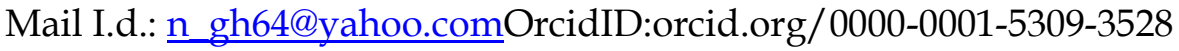

\section{Reviewer two: Ali Khanmohmmadi}

Master student of Cultural Studies at AllamehTabataba'i University in Iran.

He has carried out a number of studies in the areas of memory and trauma, sociology of art and cultural history in Iran. Latest article “ Art Immigration in Tehran's civic art during the Pahlavi Period: A Case Study of Caucasian Refugee Architects and Sculptors " was published in the Conservation of Historical Areaon Summer, 2020.

Mail I.d.: ali1992khanmohammadi@gmail.com. Orcid ID: orcid.org/0000-0003-0768-4217 